https://medium.com/@eyalronel1984/auto-scaling-real-time-nodejsapplications-on-aws-the-last-tutorial-youll-need-eba1d2c88a4c

6. Harith Javed Bakhrani Scaling Your Web Application. 2020. URL: https://medium.com/@harithjaved/scaling-your-web-application693657ce333c

7. AWS Deploying Node.js applications to Elastic Beanstalk - Developer Guide. URL: https://docs.aws.amazon.com/elasticbeanstalk/ latest/dg/create_deploy_nodejs.html

DOI https://doi.org/10.30525/978-9934-588-79-2-1.5

\title{
МЕТОДИ РІШЕННЯ ЗАВДАНЬ ПЛАНУВАННЯ ПОВЕДІНКИ АГЕНТІВ В ІНТЕЛЕКТУАЛЬНИХ СИСТЕМАХ ПІДТРИМКИ ПРИЙНЯТТЯ РІШЕНЬ
}

\author{
Демченко Є. Я. \\ кандидат технічних наук, \\ начальник науково-дослідного відділу науково-методичного \\ забезпечення розроблення і реалізації програм розвитку озброєння \\ та військової техніки та державного оборонного замовлення \\ Центрального науково-дослідного інституту озброєння \\ та військової техніки Збройних Сил Украӥни \\ м. Київ, Украӥна
}

Вступ. Необхідність проектування інтелектуальних систем прийняття/підтримки прийняття рішень (СППР) при управлінні складними об'єктами і процесами різної природи обумовлюється безперервним зростанням їх складності з одночасним скороченням часу, що відводиться людині, яка приймає рішення (ЛПР) на аналіз проблемної ситуації, ідентифікацію виниклого відхилення від нормального (штатного) режиму функціонування об'єкту, пошук можливих коригувальних рішень по впливу на об'єкт (процес), оцінку наслідків прийнятих рішень i, нарешті, видачу команд на відпрацьовування необхідних впливів.

Реалізувати СППР у повному обсязі можна лише з використанням сучасних технологій проектування інтелектуальних систем, заснованих на концепціях розподіленого штучного інтелекту, мультиагентності, динамічних баз знань, нейронних мереж, хмарних обчислень. 
Мультиагентні системи (МАC) мають великий теоретичний і практичний потенціал по створенню інтелектуальних агентів, у тому числі по створенню моделей, заснованих на реактивній поведінці, на основі планування.

Виклад основного матеріалу дослідження. Аналіз існуючих методів планування дозволяє класифікувати підходи, що використовуються, за способами взаємодії із середовищем [1-3]:

a) автономне планування - агент отримує інформацію про стан системи в деякий момент часу і на цій основі будує план, тобто весь етап планування завершується до початку виконання плану;

б) інтерактивне планування - агент використовує інформацію про поточний стан середовища в процесі складання плану, тобто можливе чергування планування і виконання плану.

Також розрізняють [1-3]: а) відкрите планування - агент не використовує інформацію про стан середовища у процесі виконання плану; б) закрите планування - у процесі виконання використовується інформація про стан середовища.

По відношенню до підцілей: а) лінійне планування - при незалежності підцілей; б) нелінійне планування - якщо між підцілями існує деяка залежність.

Існування залежностей у нелінійному плануванні приводить до необхідності організації чергування дій, спрямованих на досягнення різних підцілей. Існують наступні способи рішення даної задачі: а) відкладене підтвердження - упорядкування дій відкладається до виникнення конфлікту цілей; б) лінеаризація - перетворення цілей для досягнення лінійності; в) розподіленість - виконання плану декількома агентами.

Крім того, використовується поділ на: а) неієрархічне планування - пошук ланцюжка дій для досягнення мети (основна проблема полягає в тому, що підцілі не розрізняються по важливості - планувальник може витратити ресурси на досягнення другорядних цілей); б) ієрархічне планування - має на увазі створення планувальником ієрархії абстракцій (підцілей). Це спрощує процедуру планування спочатку створюється план загалом, потім виконується деталізація спуск по ієрархії. Виділяють два способи створення ієрархій - у просторі задач (розщеплення плану) і в просторі станів (виділення станів у класи еквівалентності). План поведінки інтелектуального агенту може бути формалізовано за допомогою графу, у якому в якості зв'язків (дуг) між вершинами виступають відношення типу «ціль -підціль», «мета - дія», «дія - результат». Шлях у графі, що веде від вершини, 
яка відповідає поточній ситуації, у кожну з цільових вершин, визначає план дій.

Усі задачі побудови плану дій можна розділити на два типи, яким відповідають різні методи: а) планування в просторі станів (SS-проблема); б) планування в просторі задач (PR-проблема). У першому випадку вважається заданим деякий простір ситуацій.

Опис ситуацій включає стан зовнішнього світу і стан середовища СППР, що характеризується множиною параметрів. Ситуації утворюють деякі узагальнені стани, а дії в СППР або зміни в зовнішньому середовищі призводять до зміни актуалізованих у даний момент станів. Серед узагальнених станів виділені початкові стани (як правило один) і кінцеві (цільові) стани. SS-проблема складається в пошуку шляху, що веде 3 початкового стану в один з кінцевих. Початковий стан - початковий рівень компетенцій. Узагальненими станами можлива послідовність розвитку компетенцій.

При плануванні в просторі задач (PR-проблема) ситуація інша. Простір утвориться в результаті введення на множині задач відношень типу «частина - ціле», «задача - підзадача», «загальний випадок частковий випадок» і т.п. Іншими словами, простір задач відображає декомпозицію задач на підзадачі (цілі на підцілі). PR-проблема для середовища СППР складається в пошуку декомпозиції вихідної задачі підготовки на підзадачі, що приводить до задач, рішення яких для ЛПР відомо.

Проведемо аналіз основних методів рішення SS - проблем. Представлення задачі в просторі станів допускає задавання ряду моделей: станів, множини операторів і їх впливів на переходи між станами, цільовими станами. Описи станів можуть представляти собою рядки символів, вектори, двомірні масиви, дерева, списки. Оператори переводять один стан в інше. Таким чином, вихідна задача розбивається на впорядковану сукупність підзадач, кожна з яких розв'язуються методом планування в просторі станів (рішення SS - проблеми). Слід зауважити, що можливі альтернативи по вибору ключових операторів, так що загальному випадку буде отримано «ТА/АБО» - графа. В більшості задач не можна виділити ключовий оператор, а лише множину, яка його містить. В такому випадку для задачі визначається розходження між станами, якому ставить у відповідність оператор, що зменшую цю різницю. Даний оператор і стає ключовим.

Проведемо аналіз основних методів рішення PR-проблем.

Планування в просторі задач полягає в послідовному зведенні вихідної задачі до усе більш простих, доти, поки не будуть отримані 
тільки елементарні задачі. Частково упорядкована сукупність таких задач складе рішення вихідної задачі. Розчленовування задачі на альтернативні множини підзадач формалізується у вигляді «ТА/АБО» графа. У такому графі усяка вершина, крім кінцевої, має або кон'юнктивно зв'язані дочірні вершини («ТА» - вершина), або диз'юнктивно зв'язані («АБО» - вершина). В окремому випадку, при відсутності «ТА»-вершин, має місце граф простору станів. Кінцеві вершини є або заключними (ім відповідають елементарні задачі), або тупиковими. Початкова вершина (корінь «ТА/АБО» графа) представляє вихідну задачу. Ціль пошуку на «ТА/АБО» - графі показати, що початкова вершина розв'язана.

Розв'язними $є$ заключні вершини («ТА»- вершини), у яких розв'язні всі дочірні вершини, і «АБО» - вершини, у яких розв'язна хоча б одна дочірня вершина. Розв'язний граф, складається 3 розв'язних вершин і вказує на спосіб можливості розв'язання початкової вершини. Наявність тупикових вершин приводить до нерозв'язних вершин. Нерозв'язними є тупикові «ТА» - вершини, у яких нерозв'язна хоча б одна дочірня вершина, а також «АБО» - вершина, у яких нерозв'язна кожна дочірня вершина.

Висновки. Задачі планування поведінки агентів в середовищі СППР, що характеризується високим динамізмом, вимагають особливої гнучкості методів інтелектуального агента. У таких системах неможливо або недостатньо знайти тільки статичний план, потрібно проводити динамічну адаптацію деякого початкового плану до динамічного середовища $\mathrm{i}$, можливо, динамічної мети безпосередньо по надходженню нової інформації, тобто розвиток вказаних в підрозділі методів лежить в площині побудови методів динамічного та адаптивного планування.

Таким чином, досліджено поточний стан методів в області МАС та виділений ряд актуальних задач, що вимагають подальших досліджень, до яких відносять: розробку моделей агентів, що самонавчаються, розробка методів колективного навчання, розробка методів нечіткого виводу в моделях спілкування і поведінки агентів.

\section{Література:}

1. Luck M., Gomez-Sanz J. Agent-oriented Software Engineering IX. 9th International Seminar, AOSE 2008, Estoril, Portugal, May 12-13, 2008. 287 p. 
2. DeLoach S.A. Moving multi-agent systems from research to practice. International Journal Agent Oriented Software Engineering. 2009. No. 4(3). Pp. 378-382.

3. Райгородский А.М. Экстремальные задачи теории графов и интернет. Москва Интеллект, 2012. 104 с.

DOI https://doi.org/10.30525/978-9934-588-79-2-1.6

\title{
КОНФІГУРАЦІЙНЕ УПРАВЛІННЯ ПРОСКТНИМИ КОМАНДАМИ
}

\author{
Доценко Н. В. \\ кандидат технічних наук, дочент, \\ дочент кафедри управління проєктами \\ в міському господарстві та будівниитві \\ Харківського національного університету міського господарства \\ імені О. М. Бекетова \\ м. Харків, Украӥна
}

Реалізація проєктів розвитку, діджіталізаціі суспільства форсується вимогами ринку, необхідністю переведення роботи в віддалений формат, організації дистанційного on-line навчання внаслідок Covid-19, однак при цьому не враховується рівень інформаційної зрілості населення і наявності доступу до Internet. Особливо гостро проблема управління проєктами в турбулентному середовищі постає при реалізації проєктів розвитку державними установами. Впровадження гнучких методологій управління проєктами структурами, які не $\epsilon$ проєктно-орієнтованими, призводить до необхідності створення бімодального управління.

Типовими проблемами управління проєктами в таких умовах є:

- використання гнучких методологій управління без детального планування, що може викликати проблеми інтеграції бюджетів на рівні організації;

- при плануванні проєкту ігнорується центр витрат «команда проекту» (вартість трудових ресурсів, що реалізують проєкт, не враховується під приводом щомісячної оплати за основним місцем роботи), що призводить до спотворення вартості проєкту, відсутності мотивації у команди проєкту;

- відсутність формалізованої системи розстановки пріоритетів в проєктах розвитку; 